\title{
Active efflux pump adeB is involved in multidrug resistance of Acinetobacter baumannii induced by antibacterial agents
}

\author{
TINGTING ZHANG, MIN WANG, YIXIN XIE, XIANPING LI, ZHIHUI DONG, \\ YANHUA LIU, LING WANG, MIN YANG, HUAN SONG, HONG CAO and WEI CAO \\ Department of Laboratory Medicine, The Second Xiangya Hospital, \\ Central South University, Changsha, Hunan 410011, P.R. China
}

Received November 18, 2015; Accepted December 19, 2016

DOI: $10.3892 /$ etm.2017.4141

\begin{abstract}
The aim of the present study was to investigate the resistance of Acinetobacter baumannii, which was induced by cefepime (FEP), cefoperazone-sulbactam (SCF), tazobactam (TZP), levofloxacin (LEV), amikacin (AK), imipenem (IPM), and ciprofloxacin (CIP), in vitro. Multi-step drug resistance selection of 16 A. baumannii strains was performed using seven antibacterial agents (FEP, TZP, CIP, AK, IPM, SCF, and LEV). The minimum inhibitory concentration (MIC) was determined using the agar dilution method. Random amplified polymorphic DNA polymerase chain reaction was performed to analyze the genotypes and the carrying rates of $\operatorname{aac}(3)-I$, aac(6')-I, ant(3)-I, aph(3)-Via, OXA-23, OXA-24, AmpC, TEM-1, metallo- $\beta$-lactamase gene (IMP), armA, rmtA, rmtB, parC, gyrA and $a d e B$. Expression of $a d e B$ was determined using semi-quantitative reverse transcription-polymerase chain reaction (Semi-qRT-PCR). Among the 16 strains, 15 strains with drug resistance $(93.8 \%)$ were obtained following in vitro induction. Notable increases (8- to 128-fold) were noted in the MIC and different genotypes were showed in RAPD of the strains before and after performing the drug resistant test. PCR data revealed significant differences $(\mathrm{P}<0.05)$ between the carrying rates of resistant genes before and after drug induction, with the exception of $r m t A, O X A-24$, TEM-1, and IMP. Significant increases were demonstrated in the comparative $a d e B$ grayscale in strains that underwent drug induction when compared with the sensitive strains $(55.69 \pm 43.11 \%$ vs. $10.08 \pm 26.35 \% ; P=0.001)$. Findings of the present study suggest that the active efflux pump, adeB, has an important role in multidrug resistance of the $A$. baumannii induced by antibacterial agents in vitro.
\end{abstract}

Correspondence to: Dr Min Wang, Department of Laboratory Medicine, The Second Xiangya Hospital, Central South University, 139 Middle Renmin Road, Changsha, Hunan 410011, P.R. China E-mail: wangmin0000@aliyun.com

Key words: Acinetobacter baumannii, drug resistance, adeB, multi-step selection

\section{Introduction}

Although carbapenems antibiotics remain the backbone therapy for severe suspected bacterial infections, resistance to this antimicrobial treatment has been increasingly reported (1). Thus, therapeutic options have become limited. Multidrug-resistance to antibiotics currently available, in particular in Gram-negative bacteria, has created a critical global medical challenge (2). Acinetobacter baumannii is frequently observed as a nosocomial infection, which causes high mortality, morbidity and hospitalization cost (3). Crude mortality rate and attributable mortality of the infection were reported to be 52 and $10-35 \%$, respectively (4). Multidrug-resistant A. baumannii is considered as a leading cause of nosocomial infection, particularly in critically ill patients (5). A. baumannii has been reported to be resistant to a broad range of antimicrobial agents, and the tendency for its epidemic spread has subsequently extended (6). An increasing drug resistance of A. baumannii to carbapenems has been demonstrated by the SENTRY Antimicrobial Surveillance Program, whose objective was to report antimicrobial susceptibility and pathogen occurrence data for $>40,000$ episodes of BSI in 72 medical centers representing 22 nations since January 1997 (7). The emergence of multidrug and pandrug-resistant $A$. baumannii has caused major threats to the infection control and treatment plans in clinical practices (8). According to our knowledge, drug resistance of A. baumannii is closely related with the application of antibacterial agents. However, few studies have been performed to investigate whether a single antibacterial agent was able to induce pandrug resistance of $A$. baumannii. In the present study, drug resistant $A$. baumannii strains were generated in vitro, once sensitive strains were induced with some commonly used antibiotics, such as FEP, SCF, TZP, LEV, AK, IPM and CIP. Findings from the current study may provide evidence for the association between the drug resistance of A. baumannii strains and antibiotics, which may provide some guidance for the treatment of A. baumannii infection.

\section{Materials and methods}

Sample collection and susceptibility tests. A total of 16 non-repeated A. baumannii strains were identified from sputum samples collected from patients at the Second Xiangya 
Hospital of Central South University (Changsha, China) between January 2010 and June 2011 (Patient characteristics are presented in Table I). Strains were sensitive to penicillins, cephalosporins, $\beta$-lactam antibiotics, carbapenems, fluoroquinolones, and aminoglycosides. All isolates were assayed for the antibiotic susceptibility of cefepime, piperacillin/tazobactam, ciprofloxacin, amikacin, imipenem, cefoperazone/sulbactam and levofloxacin, which obtained from The National Institutes for Food and Drug Control of China (Beijing, China), using the Kirby-Bauer test. Mueller-Hinton ( $\mathrm{MH}$ ) broth and agar were purchased from Guangzhou Detgerm Microbiology Technology Co., Ltd. (Guangzhou, China). Results were analyzed using the performance standards for antimicrobial susceptibility testing established by the Clinical and Laboratory Standards Institute (CLSI) (9). Minimum inhibitory concentration (MIC) was measured using the agar dilution method. Results were analyzed using the performance standards established by the CLSI in 2009. Pseudomonas aeruginosa ATCC27853 (Mecconti, Sp. Zo.o., Warsaw, Poland) was used as a quality control.

Induction of drug-resistant strains using multi-step selection. A total of 16 strains of A. baumannii that were sensitive to FEP, cefoperazone-sulbactam (SCF), tazobactam (TZP), levofloxacin (LEV), amikacin (AK), imipenem (IPM), and ciprofloxacin (CIP) antibiotics were used for the induction of drug resistance in the strains. Bacteria were suspended in sterilized isotonic saline solution to a turbidity of $0.5 \mathrm{McF}$ arland. The concentration of the suspension was modulated to $10^{9} \mathrm{CFU} / \mathrm{ml}$. Subsequently, $100 \mu 1$ suspension was inoculated onto $\mathrm{MH}$ agar plates with the seven antibiotics outlined (antibiotic concentration, 1/4 of the MIC). Following inoculation at $37^{\circ} \mathrm{C}$ for $24 \mathrm{~h}$, bacteria selected from single colonies were inoculated onto the $\mathrm{MH}$ agar plates at the same concentration as the antibiotics. Following inoculation for five generations, the resultant suspensions were inoculated onto the $\mathrm{MH}$ agar plates with a doubled concentration of antibiotics (1/2 of the MIC). The induction sequence of the drugs was FEP, SCF, TZP, IPM, AK, CIP and LEV. Sensitivity of the induced strains was determined using the Kirby-Bauer method according to the CLSI guidelines (9) and MIC detection.

DNA isolation from the A. baumannii strains. DNA from A. baumannii strains was extracted using a DNA genome extraction kit (Tiangen Biotech Co., Ltd., Beijing, China) prior to the induction of resistance to FEP, SCF, TZP, IPM, AK, CIP and LEV, according to the manufacturer's instructions. Extracted DNA was resolved in tris-ethylenediaminetetraacetic acid buffer, supplemented with RNase. Purified DNA was aliquoted and stored at $-20^{\circ} \mathrm{C}$.

Random amplified polymorphic DNA assay. Random amplified polymorphic DNA (RAPD) assay was performed using a RAPD analysis kit (GE Healthcare Life Sciences, Uppsala, Sweden). DNA was amplified by the addition of random primer AP2 with a sequence of 5'-GTTTCGCTCC-3' (10). Polymerase chain reaction (PCR) amplification was performed in a total volume of $20 \mu \mathrm{l}$, containing $50 \mathrm{ng}$ DNA template, 2X PCR mix and $2 \mu \mathrm{l}$ of the primer. Mixtures were subjected to 45 cycles of amplification $\left(95^{\circ} \mathrm{C}\right.$ for $45 \mathrm{sec}, 33^{\circ} \mathrm{C}$ for $45 \mathrm{sec}$, $72^{\circ} \mathrm{C}$ for $120 \mathrm{sec}$ for each cycle) with an initial incubation step at $95^{\circ} \mathrm{C}$ for $5 \mathrm{~min}$ and a final extension step at $72^{\circ} \mathrm{C}$ for $10 \mathrm{~min}$. Amplified fragments were separated using $1.5 \%$ agarose gel electrophoresis at $150 \mathrm{~V} / \mathrm{cm}$ for $20 \mathrm{~min}$. Images of the gels were captured under ultraviolet illumination. Subsequently, the distribution of the DNA bands obtained before and after drug induction were compared.

$P C R$ amplification for the drug-resistant genes. Sequences of $\beta$-lactamase genes (OXA-23, OXA-24, AmpC, TEM-1 and $I M P)$, fluoroquinolone resistance genes ( $\operatorname{par} C$ and $g y r A)$, aminoglycoside resistance genes [aac(3)-I, $\operatorname{aac}\left(6^{\prime}\right)-I$, ant (3')-I and $\operatorname{aph}(3)$-Via], 16S rRNA methylase genes ( $\operatorname{armA}, \mathrm{rmt} A$ and $r m t B)$, and active efflux gene ( $a d e B)$ were downloaded from Genbank (ncbi.nlm.nih.gov/genbank). Specific primers were designed according to these gene sequences. The primers (Table II) were synthesized by Sangon Biotech Co., Ltd., (Shanghai, China). PCR reactions were performed in a volume of $20 \mu \mathrm{l}$ containing 2X Taq PCR Master Mix, $10 \mu \mathrm{mol} / \mathrm{l}$ of each primer and $50 \mathrm{ng}$ DNA template. PCR conditions of each primer are listed in Table III. The amplification product was electrophoresed on a $1.5 \%$ agarose gel for $20 \mathrm{~min}$ with a voltage of $150 \mathrm{~V}$. Following DNA purification, the DNA samples were sent to Sangon Biotech Co., Ltd. for sequencing analysis. The partial sequences of parC and gyrA were compared with that of the NCBI database respectively. using BLAST analysis (accessible at: https://blast.ncbi.nlm.nih.gov/Blast.cgi).

Reverse transcription and Semi-quantitative polymerase chain reaction ( $R T$-Semi-qPCR) assay. Total mRNA of 16 induced strains and sensitive strains were extracted using a total RNA kit II (Omega Bio-Tek, Inc. Norcross, GA, USA) according to the manufacturer's protocols. RT was executed using an ReverTra Ace- $\alpha$-transcriptase purchased from Toyobo Co., Ltd., (Osaka, Japan) in a total volume of $25 \mu$, following the manufacturer's protocol. PCR was performed in a volume of $20 \mu \mathrm{l}$, comprising $2 \mu \mathrm{l}$ cDNA. The mRNA expression of active efflux gene $a d e B$ was normalized to $16 \mathrm{~S}$ rRNA. The following cycling conditions were used, adeB: $95^{\circ} \mathrm{C}$ for $5 \mathrm{~min}$, then 35 cycles of $95^{\circ} \mathrm{C}$ for $30 \mathrm{sec}, 53^{\circ} \mathrm{C}$ for $60 \mathrm{sec}$ and $72^{\circ} \mathrm{C}$ for $90 \mathrm{sec}$, followed by $72^{\circ} \mathrm{C}$ for $4 \mathrm{~min} ; 16 \mathrm{~S} \mathrm{rRNA}: 95^{\circ} \mathrm{C}$ for $5 \mathrm{~min}$, 35 cycles of $94^{\circ} \mathrm{C}$ for $30 \mathrm{sec}, 55^{\circ} \mathrm{C}$ for $40 \mathrm{sec}$ and $72^{\circ} \mathrm{C}$ for $45 \mathrm{sec}$, followed by $72^{\circ} \mathrm{C}$ for $4 \mathrm{~min}$. The primers used for $16 \mathrm{~S}$ rRNA downloaded from Genbank (accessible at:https://www. ncbi.nlm.nih.gov/genbank/) were forward 5'-GTTATTAGG GAAGAACATATGTG-3' and reverse 5'-CCACCTTCC TCCGGTTTGTCACC-3'. And the primers used for adeB were forward 5'-AAAGACTTCAAAGAGCGGACTA-3' and reverse 5'-ATTGTCACCTTGTGGCAACCCT-3'. The cDNA amplification product was electrophoresed on a $1.5 \%$ agarose gel. Subsequently, the electrophoretic grayscale were analyzed to assess the product sizes using Quantity One 4.4.0 software (Bio-Rad Laboratories, Inc., Hercules, CA, USA) and presented as a mean \pm standard deviation

Statistical analysis. SPSS 17.0 software (SPSS, Inc., Chicago, IL, USA) was used for statistical analysis. The rate of induced strains resistant to each antibiotic and carrying rate of drug-resistant genes were presented as percentages. 
Table I. The patient characteristics of the 16 Acinetobacter baumannii strains obtained.

\begin{tabular}{|c|c|c|c|c|c|}
\hline Case & Gender & $\begin{array}{l}\text { Age, } \\
\text { years }\end{array}$ & Sample & Department & Main diagnosis \\
\hline 1 & Male & 43 & sputum & Department of hematology & M3 acute myeloid leukemia; Lung infection \\
\hline 2 & Male & 80 & sputum & Department of senile disease & $\begin{array}{l}\text { Acute exacerbation of chronic obstructive } \\
\text { pulmonary disease }\end{array}$ \\
\hline 3 & Male & 73 & sputum & Department of nephrology & Nephrotic syndrome; Lung infection \\
\hline 4 & Male & 80 & sputum & Department of senile disease & $\begin{array}{l}\text { Acute exacerbation of chronic obstructive } \\
\text { pulmonary disease }\end{array}$ \\
\hline 5 & Male & 88 & sputum & Department of senile disease & $\begin{array}{l}\text { Acute exacerbation of chronic obstructive } \\
\text { pulmonary disease }\end{array}$ \\
\hline 6 & Male & 78 & sputum & Department of senile disease & Interstitial lung disease; Lung infection \\
\hline 7 & Male & 52 & sputum & Department of respiratory medicine & Severe pneumonia \\
\hline 8 & Male & 39 & sputum & ICU & Lung infection after renal transplantation \\
\hline 9 & Male & 77 & sputum & Department of senile disease & Type 2 respiratory failure and Lung infection \\
\hline 10 & Male & 44 & sputum & Department of hematology & Multiple myeloma; Lung infection \\
\hline 11 & Male & 56 & sputum & Department of nephrology & Diabetic nephropathy; Lung infection \\
\hline 12 & Male & 60 & sputum & Department of senile disease & Acute exacerbation of chronic bronchitis \\
\hline 13 & Male & 88 & sputum & Department of senile disease & $\begin{array}{l}\text { Acute exacerbation of chronic obstructive } \\
\text { pulmonary disease }\end{array}$ \\
\hline 14 & Male & 57 & sputum & Department of respiratory medicine & Community-acquired pneumonia \\
\hline 15 & Male & 70 & sputum & Department of neurology & Cerebral hemorrhage; Lung infection \\
\hline 16 & Male & 33 & sputum & Department of infectious diseases & Lung abscess \\
\hline
\end{tabular}

Chi-square test was used for comparing the carrying rate of drug resistance genes. Student's t-test was performed for the expression of $a d e B$ mRNA. $\mathrm{P}<0.05$ was considered to indicate a statistically significant difference. The electrophoretic grayscale of $a d e B$ was presented as a mean \pm standard deviation. Each experiment was repeated 3 times.

\section{Results}

Source and distribution of the strains. A total of 16 strains were isolated from sputum samples obtained from the Department of Senile Disease (43.8\%), ICU (6.25\%), Department of Respiratory Medicine (12.5\%), Department of Hematology (12.5\%), Department of Nephrology (12.5\%), Department of Infectious Diseases (6.25\%) and Department of Neurology (6.2\%), respectively, at the Second Xiangya Hospital of Central South University.

MIC of the strains following induction in vitro. Among the 16 strains, 15 strains $(93.8 \%)$ acquired drug resistance following in vitro induction. Five strains were resistant to all the drugs, while 8 strains were resistant to $\geq 5$ drugs, and 2 strains were resistant to $<5$ drugs. Table IV summarizes the MICs of the 16 strains before and after in vitro induction using FEP, SCF, TZP, LEV, AK, IPM, and CIP, respectively. The number of strains resistant to FEP, CIP, LEV, AK, TZP, SCF, and IPM were 13 (81.3\%), 12 (75.0\%), 11 (68.8\%), 11 (68.8\%), $9(56.3 \%), 8(50.0 \%)$, and (43.8\%), respectively. Minimum drug resistance of the strains was noted in IPM, followed by SCF and TZP. Following drug induction, a decrease was observed in the size of the inhibition zone generated by all the induced strains, and an increase was noted in the MIC to each drug (Table IV).

Genotyping of AP2. As the RAPD results indicate in Fig. 1, genotyping of the strains varied depending on the original non-induced strains (16 sensitive strains) and those obtained after induction in vitro.

Identification of the drug resistance genes. With the exception of four drug resistant genes ( $r m t A, I M P, T E M-1$, and OXA-24), a significantly increased positive rate of gene amplification was noted in the induced strains when compared with drug-susceptible strains $(\mathrm{P}<0.05$; Fig. 2; Table V). The present study showed that acquired drug resistance was achieved in A. baumannii following exposure to low concentrations of antibiotics, in vitro. Moreover, significant differences were exhibited in the amplification results of adeB in $A$. baumannii following in vitro induction when compared with the results obtained from the strains without in vitro induction $\left(\chi^{2}=20.257\right.$; $\mathrm{P}<0.05$; Table V).

PCR amplification and restriction map of gyrA and parC. Following drug induction using fluoroquinolone antibiotics, CIP and LEV, PCR results revealed the amplification of gyr $A$ and $\operatorname{par} C$ before and after induction was positive. Following digestion using Hinf1, gyrA fragments, obtained from 10 drug-sensitive strains $(10 / 16 ; 62.5 \%)$ generated two bands (225 and $80 \mathrm{bp}$, Fig. 3A), while the gyrA fragments, obtained from the 11 drug resistant strains, were not digested by Hinf1. parC fragments obtained from the drug resistant strains $(3 / 12$; $25.0 \%)$ and sensitive strains $(11 / 16 ; 68.7 \%)$ were digested into 
Table II. Primers used in polymerase chain reaction amplification and the lengths of the resultant fragments.

\begin{tabular}{|c|c|c|c|}
\hline Gene & Primer & Primer sequence & Length of product, bp \\
\hline TEM-1 & $\begin{array}{l}\text { Sense } \\
\text { Anti }\end{array}$ & $\begin{array}{l}\text { TTCGTGTCGCCCTTATTC } \\
\text { ACGCTCGTCGTTTGGTAT }\end{array}$ & 512 \\
\hline$I M P$ & $\begin{array}{l}\text { Sense } \\
\text { Anti }\end{array}$ & $\begin{array}{l}\text { CTACCGCAGCAGAGTCTTTG } \\
\text { AACCAGTTTTGCCTTACCAT }\end{array}$ & 587 \\
\hline OXA-23 & $\begin{array}{l}\text { Sense } \\
\text { Anti }\end{array}$ & $\begin{array}{l}\text { TGTCATAGTATTCGTCGTT } \\
\text { TTCCCAAGCGGTAAA }\end{array}$ & 453 \\
\hline$O X A-24$ & $\begin{array}{l}\text { Sense } \\
\text { Anti }\end{array}$ & $\begin{array}{l}\text { TTTGCCGATGACCTT } \\
\text { TAGCTTGCTCCACCC }\end{array}$ & 175 \\
\hline$A m p C$ & $\begin{array}{l}\text { Sense } \\
\text { Anti }\end{array}$ & $\begin{array}{l}\text { CGACAGCAGGTGGAT } \\
\text { GGTTAAGGTTGGCATG }\end{array}$ & 510 \\
\hline $\operatorname{aac}(3)-I$ & $\begin{array}{l}\text { Sense } \\
\text { Anti }\end{array}$ & $\begin{array}{l}\text { ACCTACTCCCAACATCAGCC } \\
\text { ATATAGATCTCACTACGCGC }\end{array}$ & 158 \\
\hline $\operatorname{aac}\left(6^{\prime}\right)-I$ & $\begin{array}{l}\text { Sense } \\
\text { Anti }\end{array}$ & $\begin{array}{l}\text { TATGAGTGGCTAAATCGA } \\
\text { CCCGCTTTCTCGTAGCA }\end{array}$ & 395 \\
\hline $\operatorname{ant}(3)-I$ & $\begin{array}{l}\text { Sense } \\
\text { Anti }\end{array}$ & $\begin{array}{l}\text { TGATTTGCTGGTTACGGTGAC } \\
\text { CGCTATGTTCTCTTGCTTTTG }\end{array}$ & 284 \\
\hline $\operatorname{aph}(3)-V I a$ & $\begin{array}{l}\text { Sense } \\
\text { Anti }\end{array}$ & $\begin{array}{l}\text { ATACAGAGACCACCATACAGT } \\
\text { GGACAATCAATAATAGCAAT }\end{array}$ & 234 \\
\hline $\operatorname{arm} A$ & $\begin{array}{l}\text { Sense } \\
\text { Anti }\end{array}$ & $\begin{array}{l}\text { GGGGTCTTACTATTCTG } \\
\text { TTCCСТTCTCСТTTC }\end{array}$ & 503 \\
\hline$r m t A$ & $\begin{array}{l}\text { Sense } \\
\text { Anti }\end{array}$ & $\begin{array}{l}\text { CCTAGCGTCCATCCTTTCCTC } \\
\text { AGCGATATCCAACACACGATGG }\end{array}$ & 315 \\
\hline$r m t B$ & $\begin{array}{l}\text { Sense } \\
\text { Anti }\end{array}$ & $\begin{array}{l}\text { ATGAACATCAACGATGCCCTC } \\
\text { TTATCCATTCTTTTTTATCAAGTATAT }\end{array}$ & 756 \\
\hline gyrA & $\begin{array}{l}\text { Sense } \\
\text { Anti }\end{array}$ & $\begin{array}{l}\text { GCTGGCTAACGGTAACTC } \\
\text { GGCTTCAATGGGACTG }\end{array}$ & 305 \\
\hline $\operatorname{parC}$ & $\begin{array}{l}\text { Sense } \\
\text { Anti }\end{array}$ & $\begin{array}{l}\text { CTGAACAGGCTTACTTGAA } \\
\text { AAGTTATCTTGCCATTCG }\end{array}$ & 400 \\
\hline AdeB & $\begin{array}{l}\text { Sense } \\
\text { Anti }\end{array}$ & $\begin{array}{l}\text { TACCGGTATTACCTTTGCCGGA } \\
\text { GTCTTTAAGTGTCGTAAAAGCCAC }\end{array}$ & 250 \\
\hline
\end{tabular}

IMP, metallo- $\beta$-lactamase gene.

two bands (205 and $195 \mathrm{bp}$, were displayed as one band due to it's similar molecular weight; Fig. 3B).

Sequence analyses of gyrA and parC. Following sequencing, the partial sequences were compared with that of the NCBI database using BLAST analysis (https://blast.ncbi.nlm.nih. gov/Blast.cgi). Results indicated nucleotide (nt) $242 \mathrm{C} / \mathrm{T}$ and $275 \mathrm{C} / \mathrm{T}$ were in the cutting site of Hinf1 in $g y r A$ of the strains that underwent drug induction, which induced the substitution of serine 81 to leucine, and threonine 92 to methionine (Fig. 4). However, no gene mutation was noted in the cutting site of the Hinf1. The nt $251 \mathrm{C} / \mathrm{T}$ was exhibited in the cutting site of Hinf 1 in parC of the strains that underwent drug induction, which induced the substitution of serine 84 to leucine (Fig. 5A and B). However, multiple synonymous mutations were observed, such as nt $297 \mathrm{~T} / \mathrm{C}$, nt
$300 \mathrm{~T} / \mathrm{C}$, nt $306 \mathrm{G} / \mathrm{T}$, nt $307 \mathrm{C} / \mathrm{T}$, nt $312 \mathrm{~T} / \mathrm{T}$, and nt $318 \mathrm{~A} / \mathrm{T}$ (Fig. 5C and D).

Expression of adeB $m R N A$. Semi-qRT-PCR indicated the lengths of the amplified fragments for $a d e B$ and 16S rRNA were 273 and $750 \mathrm{bp}$, respectively. The relative grayscale was calculated according to the Quantity One 4.4.0 software. Compared with the mRNA expression levels of the sensitive strains, significant differences were observed in the $a d e B$ mRNA expression of drug-induced strains $(55.69 \pm 43.11 \%$ vs. 10.08 $\pm 26.35 \%$; $\mathrm{P}<0.05$; Fig. 6).

\section{Discussion}

A. baumannii, which is a gram-negative, non-fermentative coccobacillus of the family Moraxellaceae, is considered to be 
Table III. Polymerase chain reaction thermal cycling conditions.

\begin{tabular}{|c|c|c|c|c|c|c|}
\hline Gene & Pre-denaturation & Denaturation & Annealing & Extension & Cycles & Final extension \\
\hline TEM-1 & $94(5 \mathrm{~min})$ & $94(60 \mathrm{sec})$ & $55(60 \mathrm{sec})$ & $72(50 \mathrm{sec})$ & 30 & $72(7 \mathrm{~min})$ \\
\hline$I M P$ & $94(5 \mathrm{~min})$ & $94(60 \mathrm{sec})$ & $55(60 \mathrm{sec})$ & $72(50 \mathrm{sec})$ & 30 & $72(7 \mathrm{~min})$ \\
\hline$O X A-23$ & $94(5 \mathrm{~min})$ & $94(30 \mathrm{sec})$ & $48(30 \mathrm{sec})$ & $72(35 \mathrm{sec})$ & 30 & $72(7 \mathrm{~min})$ \\
\hline$O X A-24$ & $94(5 \mathrm{~min})$ & $94(30 \mathrm{sec})$ & $48(30 \mathrm{sec})$ & $72(35 \mathrm{sec})$ & 30 & $72(7 \mathrm{~min})$ \\
\hline AmpC & 94 (5 min) & $94(30 \mathrm{sec})$ & $50(30 \mathrm{sec})$ & $72(50 \mathrm{sec})$ & 30 & $72(7 \mathrm{~min})$ \\
\hline $\operatorname{aac}(3)-I$ & 94 (4 min) & $94(30 \mathrm{sec})$ & $55(30 \mathrm{sec})$ & $72(60 \mathrm{sec})$ & 35 & $72(7 \mathrm{~min})$ \\
\hline $\operatorname{aac}\left(6^{\prime}\right)-I$ & 94 (4 min) & $94(30 \mathrm{sec})$ & $55(30 \mathrm{sec})$ & $72(60 \mathrm{sec})$ & 35 & $72(7 \mathrm{~min})$ \\
\hline $\operatorname{ant}(3)-I$ & 94 (4 min) & $94(30 \mathrm{sec})$ & $55(30 \mathrm{sec})$ & $72(60 \mathrm{sec})$ & 35 & $72(7 \mathrm{~min})$ \\
\hline $\operatorname{aph}(3)-V I a$ & $93(2 \mathrm{~min})$ & $93(20 \mathrm{sec})$ & $55(30 \mathrm{sec})$ & $72(30 \mathrm{sec})$ & 30 & $72(5 \mathrm{~min})$ \\
\hline $\operatorname{armA}$ & 94 (5 min) & $94(30 \mathrm{sec})$ & 47 (30 sec) & $72(50 \mathrm{sec})$ & 30 & $72(5 \mathrm{~min})$ \\
\hline$r m t A$ & $93(2 \mathrm{~min})$ & $93(20 \mathrm{sec})$ & $55(30 \mathrm{sec})$ & $72(30 \mathrm{sec})$ & 30 & $72(5 \mathrm{~min})$ \\
\hline$r m t B$ & $93(2 \mathrm{~min})$ & $93(20 \mathrm{sec})$ & $50(60 \mathrm{sec})$ & $72(60 \mathrm{sec})$ & 30 & $72(5 \min )$ \\
\hline gyrA & 94 (4 min) & 94 (30 sec) & $55(30 \mathrm{sec})$ & $72(40 \mathrm{sec})$ & 30 & $72(7 \mathrm{~min})$ \\
\hline $\operatorname{parC}$ & 94 (4 min) & 94 (30 sec) & $53(30 \mathrm{sec})$ & $72(40 \mathrm{sec})$ & 30 & $72(7 \mathrm{~min})$ \\
\hline$a d e B$ & $95(5 \mathrm{~min})$ & $95(30 \mathrm{sec})$ & $53(60 \mathrm{sec})$ & 72 (90 sec) & 30 & $72(7 \mathrm{~min})$ \\
\hline
\end{tabular}

Data are presented as ${ }^{\circ} \mathrm{C}$ (duration). IMP, metallo- $\beta$-lactamase gene.

Table IV. MIC of the 16 strains prior to and following drug induction.

\begin{tabular}{|c|c|c|c|c|c|c|c|}
\hline Strain & FEP & $\mathrm{SCF}$ & $\mathrm{TZP}$ & LEV & AK & IPM & CIP \\
\hline 1 & $2 / 32$ & $2 / 64$ & $4 / 64$ & $0.5 / 8$ & $8 / 64$ & $2 / 16$ & $0.5 / 32$ \\
\hline 2 & $2 / 16$ & $2 / 32$ & $4 / 64$ & $0.5 / 8$ & $16 / 128$ & $4 / 64$ & $0.5 / 32$ \\
\hline 3 & $2 / 16$ & $4 / 64$ & $8 / 64$ & $0.5 / 8$ & $8 / 64$ & $0.5 / 8$ & $0.5 / 32$ \\
\hline 4 & $2 / 32$ & $2 / 64$ & $8 / 64$ & $0.5 / 8$ & $8 / 64$ & $8 / 128$ & $0.5 / 16$ \\
\hline 5 & $4 / 32$ & $4 / 128$ & $4 / 64$ & $0.5 / 8$ & $2 / 16$ & $2 / 16$ & $0.25 / 32$ \\
\hline 6 & $2 / 32$ & $4 / 64$ & $4 / 64$ & $0.5 / 8$ & $4 / 128$ & - & $0.5 / 16$ \\
\hline 7 & $4 / 64$ & $4 / 32$ & $8 / 64$ & $1 / 8$ & $8 / 64$ & - & $1 / 16$ \\
\hline 8 & $4 / 32$ & - & $8 / 64$ & $1 / 8$ & $8 / 64$ & - & $0.5 / 64$ \\
\hline 9 & $2 / 32$ & - & - & $0.5 / 16$ & $8 / 128$ & - & $0.5 / 32$ \\
\hline 10 & $2 / 32$ & - & - & $0.5 / 8$ & $8 / 128$ & - & $0.5 / 16$ \\
\hline 11 & $2 / 64$ & $4 / 64$ & $4 / 64$ & - & - & - & - \\
\hline 12 & $4 / 64$ & - & - & - & - & $2 / 64$ & - \\
\hline 13 & $4 / 64$ & - & - & - & $8 / 64$ & $2 / 64$ & - \\
\hline 14 & - & - & - & $0.5 / 4$ & - & - & $0.5 / 16$ \\
\hline 15 & - & - & - & - & - & - & $0.5 / 16$ \\
\hline 16 & - & - & - & - & - & - & - \\
\hline
\end{tabular}

Indicated by MIC values, presented as the initial MIC/MIC following treatment in $\mu \mathrm{g} / \mathrm{ml}$. MIC, minimum inhibitory concentration; FEP, cefepime; SCF, cefoperazone-sulbactam; TZP, tazobactam; LEV, levofloxacin; AK, amikacin; IPM, imipenem; CIP, ciprofloxacin.

an important cause of ventilator-associated pneumonia, sepsis, urinary system infection and meningitis (11-17). Currently, no approved antimicrobial drugs have been successfully developed to treat A. baumannii, as it exhibits multidrug resistance. In the present study, 16 A. baumannii strains were isolated from the Department of Senile Disease (43.8\%), ICU (12.5\%), Department of Respiratory Medicine (12.5\%), Department of Hematology (12.5\%), Department of Nephrology (12.5\%), and Department of
Neurology (6.2\%), respectively, at the Second Xiangya Hospital of Central South University. The majority of strains were isolated from the ICU and the Department of Respiratory Medicine in a previous study (18). We speculated that this descrepency may be due to the strains selected in this study. Moreover, the strains were exclusively isolated from sputum samples, demonstrating that A. baumannii may be an important cause for respiratory tract infection and was similar to a previous study using 
A

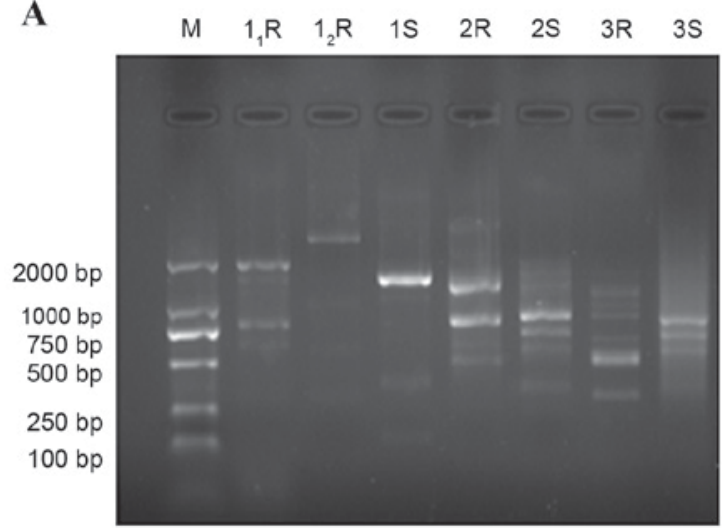

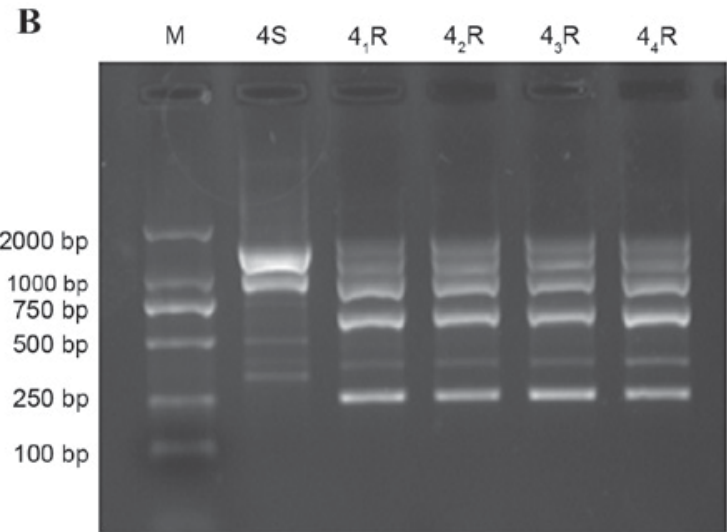

Figure 1. Genotype of Acinetobacter baumannii before and after drug induction. (A) $1 \mathrm{~S}, 2 \mathrm{~S}, 3 \mathrm{~S}$ and $4 \mathrm{~S}$, strains prior to drug induction; $1_{1} \mathrm{R}, 1_{2} \mathrm{R}$, drug-resistant strain number $1 ; 2 \mathrm{R}$, drug-resistant strain number $2 ; 3 \mathrm{R}$, drug-resistant strain number 3 and $(\mathrm{B}) 4_{1} \mathrm{R}, 4_{2} \mathrm{R}, 4_{3} \mathrm{R}$ and $4_{4} \mathrm{R}$, drug-resistant strain number 4 $\mathrm{M}$, marker; S, prior to induction; R, following induction.
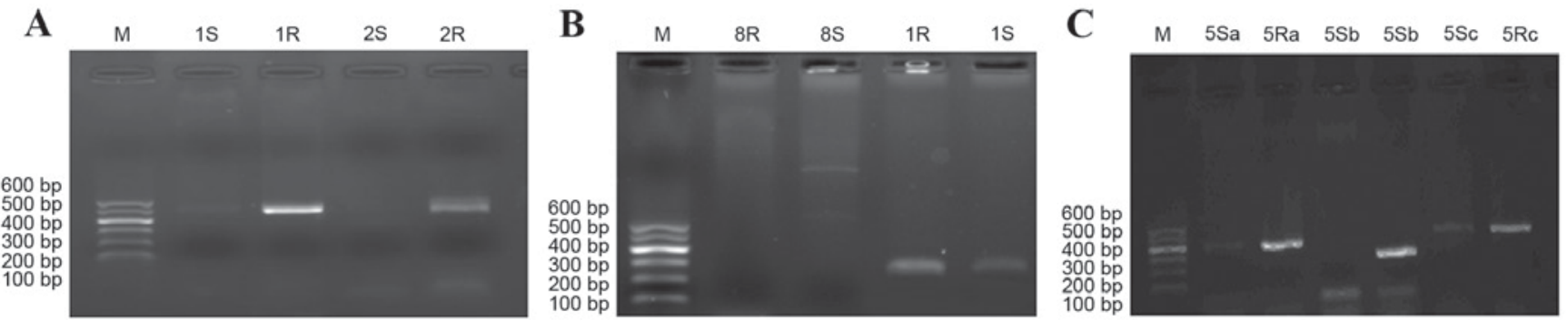

Figure 2. Polymerase chain reaction amplification results of the Acinetobacter baumanniis strains following drug induction. (A) Amplification results of the armA gene before (1S and $2 \mathrm{~S}$ ) and after (1R and 2R) and drug induction. (B) Amplification results of the adeB gene before (1S and 8S) and after (1R and 8R) drug induction. (C) amplification results for aac (6')-I, ant( $\left.3^{\prime \prime}\right)-I, O X A-23$ before (5Sa, 5Sb, and 5Sc) and after (5Ra, 5Rb and 5Rc) drug induction. M, marker.

sputum samples from patients with pneumonia as a source of Acinetobacter baumannii (18). Thus, more attention is required when monitoring the respirator and the nursing staff to prevent respiratory tract infections in these Departments.

The mechanism of how A. baumannii develops resistance towards multiple drugs has been extensively studied (19-21). The mechanisms underlying resistance to multiple drugs in A. baumannii have been identified to include i) the capacity to generate enzymes that may inactivate the antibacterial agents; ii) changes in the antibacterial-binding proteins that prevent their action; iii) alternations in the structure and number of porin proteins that lead to decreased permeability to antibacterial agents; and iv) the activity of efflux pumps that further reduce the concentration of antibacterial agents within the bacterial cell. It has been well-acknowledged that the long-term exposure to various antibiotics is the major reason for the formation of multidrug-resistant A. Baumannii (6). However, few studies have investigated the mechanism of how drug resistance is established. With the large-scale application of antibacterial agents, multidrug-resistant bacteria have been compared with bacteria that are sensitive to antibacterial agents. To date, various multidrug-resistant bacteria have been detected. For example, resistant Pseudomonas aeruginosa and Streptococcus pyogenes have been induced in vitro, using various agents such as gentamicin, ciprofloxacin, and azithromycin (22-26).

In the present study, multi-step selection was used for the induction of drug-resistant bacteria to avoid the specificity of the induction. Furthermore, the growth and disperse pattern of the bacteria in vivo was mimicked in our study. The initial induction concentration was 1/4 MIC, which revealed similarity with the low dose clinical medication administered in our clinical practices (27). A total of 15 strains $(98.3 \%)$ resistant to FEP, SCF, TZP, IPM, AK, CIP and LEV were collected following exposure to increasing concentrations of the agent. Moreover, sharp increases were noted in the MIC to these agents post-induction. These results indicated that significant differences were observed in the drug-resistant phenotype of A. baumannii in the presence of antibiotics. Additionally, the drug tolerance of the strains was comparatively stable. Significant cross resistance was exhibited in the strains collected in the present study. Our study was consistent with previous reports $(23,28)$.

The genotype and drug-resistant genes were analyzed before and after drug induction. The results of the present study revealed statistical differences in the drug resistance genes and genotyping. Moreover, a significantly increased positive rate was observed in the $\beta$-lactamase gene in strains subjected to drug induction, particularly $O X A-23$ (64.9\%) and $A m p C$ (91.9\%). To our knowledge, $O X A$-23-producing A. baumannii was resistant to IPM (29-36). AmpC enzyme was encoded by chromogene, and it's over expression could induce drug resistance towards penicillin and the third generation broad-spectrum cephalosporins, through hydrolysis. We speculated that $O X A-23$ and $A m p C$ may be associated with drug resistance towards FEP, SCF, TZP, and IPM as an increased positive rate was observed in $O X A-23$ and $A m p C$. In A. baumannii, aminoglycosides modifying 
Table V. Carrying rates of drug resistance gene in sensitive strains and induced strains.

\begin{tabular}{|c|c|c|c|c|}
\hline Gene & $\begin{array}{l}\text { Carrying rates in } \\
\text { sensitive strains }\end{array}$ & $\begin{array}{l}\text { Carrying rates in } \\
\text { induced strains }\end{array}$ & $\chi^{2}$ & P-value \\
\hline $\operatorname{aac}(3)-I$ & $12.5(2 / 16)$ & $54.5(6 / 11)$ & - & 0.027 \\
\hline $\operatorname{aac}(6)-I$ & $18.8(3 / 16)$ & $63.6(7 / 11)$ & - & 0.024 \\
\hline $\operatorname{ant}(3)-I$ & $6.3(1 / 16)$ & $81.8(9 / 11)$ & - & 0.000 \\
\hline $\operatorname{aph}(3)$ & $6.3(1 / 16)$ & $54.5(6 / 11)$ & - & 0.009 \\
\hline $\operatorname{armA}$ & $12.5(2 / 16)$ & $90.9(10 / 11)$ & - & 0.000 \\
\hline$r m t A$ & $18.8(3 / 16)$ & $45.5(5 / 11)$ & - & 0.144 \\
\hline$r m t B$ & $12.5(2 / 16)$ & $54.5(6 / 11)$ & - & 0.027 \\
\hline$I M P$ & $25.0(4 / 16)$ & $27.0(10 / 37)$ & 0.024 & 0.582 \\
\hline TEM-1 & $68.8(11 / 16)$ & $81.1(30 / 37)$ & 0.970 & 0.261 \\
\hline$O X A-24$ & $37.5(6 / 16)$ & $43.2(16 / 37)$ & 0.152 & 0.469 \\
\hline$O X A-23$ & $18.8(3 / 16)$ & $64.9(24 / 37)$ & 9.505 & $<0.05$ \\
\hline$A m p C$ & $50.0(8 / 16)$ & $91.9(34 / 37)$ & 11.918 & $<0.05$ \\
\hline gyrA & $100.0(16 / 16)$ & $100.0(11 / 11)$ & - & - \\
\hline parC & $100.0(16 / 16)$ & $100.0(12 / 12)$ & - & - \\
\hline$a d e B$ & $18.8(3 / 16)$ & $78.6(56 / 71)$ & 20.257 & $<0.05$ \\
\hline
\end{tabular}

Data are presented as percentage (number of genes carried strains/total strains).

A

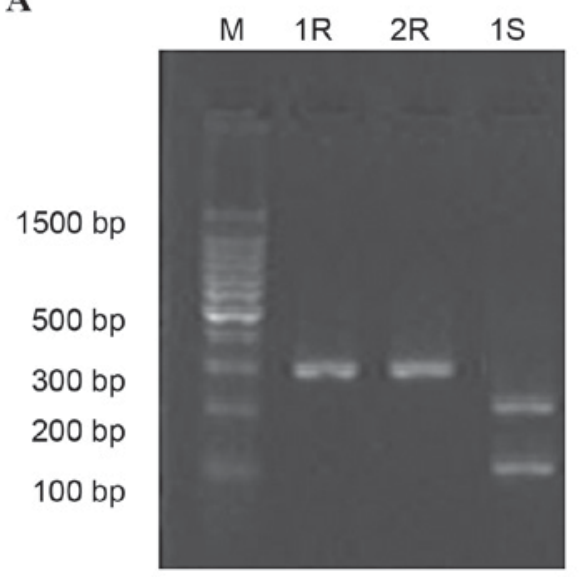

B

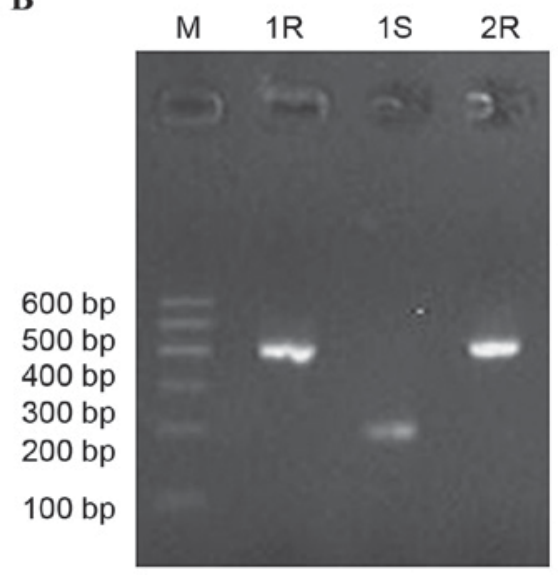

Figure 3. Digestion analyses of (A) gyrA and (B) parC using Hinf1. M, marker; R, resistant strains; S, sensitive strains.
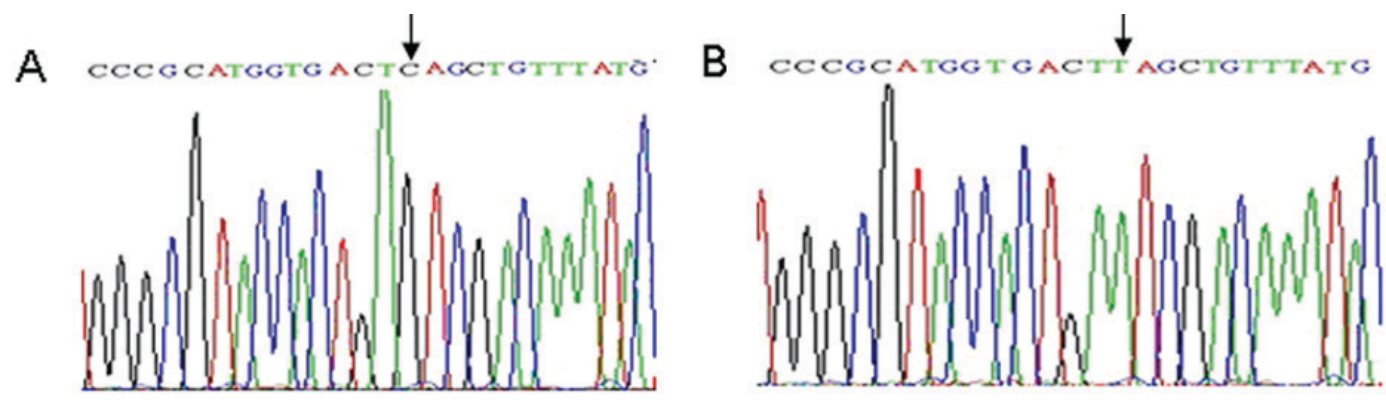

Figure 4. Comparison alignment of cut and uncut strains with gyrA. The arrow indicates a nucleotide C/T change in the site of Hinf1 in gyrA of the strains (A) prior to and (B) following drug induction.

enzyme genes, such as $A A C(3)-I, A A C\left(6^{\prime}\right)-I$ and $A N T\left(3^{\prime}\right)-I$, and $16 S$ rRNA methylase gene, including $\operatorname{arm} A, r m t A, r m t B$, and $q p h$ (3), were revealed to induce the drug resistance towards the aminoglycoside antibiotics. This type of drug resistance may 

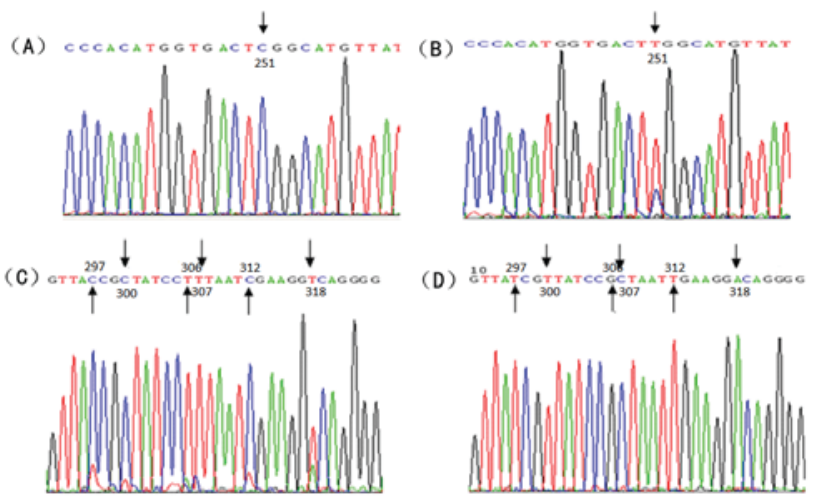

Figure 5. Comparison alignment of cut and uncut strains with $\operatorname{ParC}$ exhibited multiple synonymous mutations. The arrow in $\mathrm{A}$ and $\mathrm{B}$ indicate a nucleotide $\mathrm{C} / \mathrm{T}$ change in the site of Hinf1 in ParC of the strains (A) prior to and (B) following drug induction. The arrows in $\mathrm{C}$ and $\mathrm{D}$ indicate multiple synonymous mutations (C) prior to and (D) following drug induction.

be related with horizontal transmission of the drug-resistant genetic locus induced by plasmid or transposon. The present findings indicated that statistical differences were observed in the carrying rate of $\operatorname{arm} A$ and $r m t B$. Based on the present data, the expression of the aminoglycoside resistance genes was suggested to be a major cause for the drug resistance to the aminoglycosides demonstrated herein. In addition, gyrA and $\operatorname{parC}$ were isolated in all strains, and gene mutations of these genes may be associated with the formation of drug resistance $(29,32)$. As the efflux pump, which is located in the outer membrane, has been suggested to have an important role in multidrug resistance capacity in bacteria (31-33), the expression of the active efflux gene $a d e B$ was determined. The resistance-nodulation-cell-division-type multidrug efflux pump, adeb, was associated with aminoglycoside resistance and has previously been implicated in mediating the level of susceptibility towards other drugs, such as tetracyclines, chloramphenicol, erythromycin, trimethoprim, and ethidium bromide (34). In the present study, a significant increase was noted in the carrying rate of $a d e B$ following in vitro induction; furthermore, significant differences were exhibited in the expression of $a d e B$ in strains that underwent drug induction when compared with the sensitive strains, which implied that the efflux pump has a crucial role in the drug resistance of A. baumannii. Notably, specific drug-resistant genes were also isolated in A. baumannii obtained from the clinical practices. However, no drug resistance was noted, which may be related to the lack of expression and low-level expression of these genes.

In the present study, notable differences were observed in the traits of colonies following in vitro induction. Compared with the colonies formed prior to drug induction, the profile of colonies were smaller in a pattern of slow growth. This demonstrated that the growth of the A. baumannii was notably affected by the antibiotics. Further studies are required to validate whether the pathogenicity of $A$. baumannii increases in the presence of increased drug resistance to antibiotics.

In conclusion, the present study established a drug resistant $A$. baumannii model following in vitro induction, using multiple-step methods. Furthermore, the active efflux pump may be involved in the development of drug resistance in A. baumannii in vitro. This study may provide
A

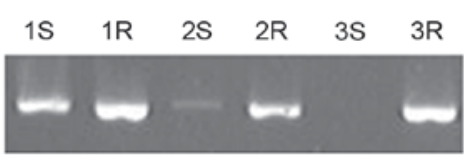

16S rRNA

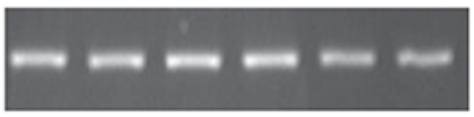

B

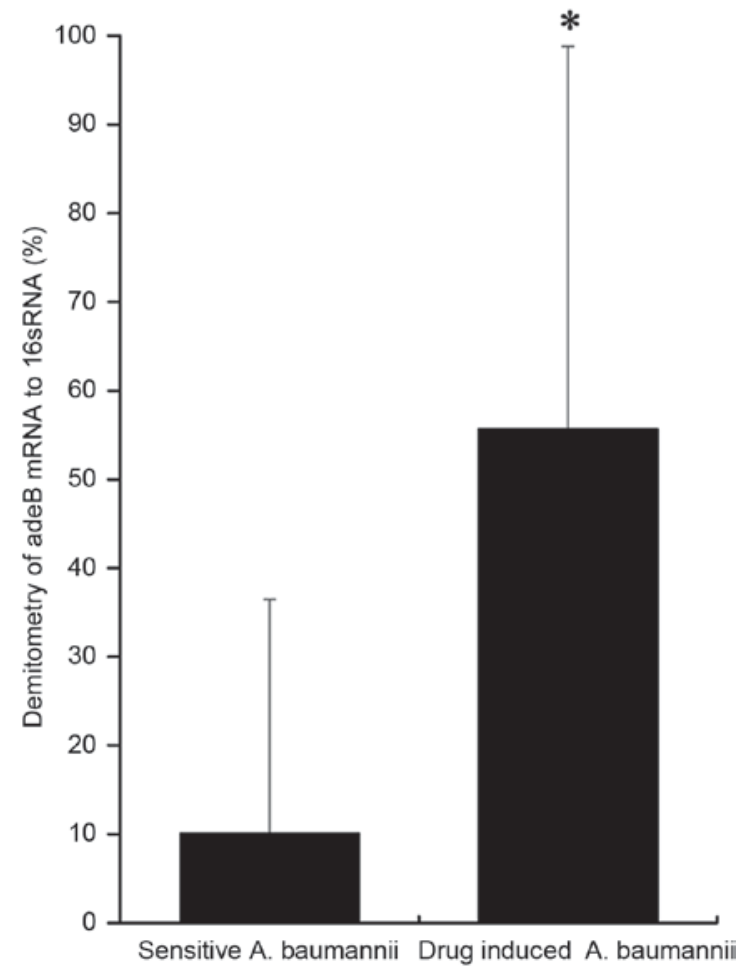

Figure 6. Expression of adeB mRNA in A. baumannii following drug induction. (A) $1 \mathrm{~S}, 1 \mathrm{R}, 2 \mathrm{~S}, 2 \mathrm{R}, 3 \mathrm{~S}$ and $3 \mathrm{R}$ : Amplification result of the adeB gene prior to and following drug induction. (B) Mean optical density of the adeB mRNA expression prior to and following induction. ${ }^{*} \mathrm{P}<0.05$, vs. sensitive strains. Data is presented as mean \pm standard deviation. A. baumannii, Acinetobacter baumanniis.

useful information for the drug resistance mechanism of the A. baumannii; however, further studies are necessary to fully elucidate the drug resistance of A. baumannii in vivo.

\section{Acknowledgments}

The present study was supported by the China National Natural Scientific Foundation (grant no. 81470133), and the Science and Technology Planning Project of Hunan Province of China (grant no. 2015JC3035).

\section{References}

1. Bou G, Cerveró G, Domínguez MA, Quereda C and Martínez-Beltrán J: Characterization of a nosocomial outbreak caused by a multiresistant Acinetobacter baumannii strain with a carbapenem-hydrolyzing enzyme: High-level carbapenem resistance in A. Baumannii is not due solely to the presence of beta-lactamases. J Clin Microbiol 38: 3299-3305, 2000.

2. Levin AS: Multiresistant Acinetobacter infections: A role for sulbactam combinations in overcoming an emerging worldwide problem. Clin Microbiol Infect 8: 144-153, 2002. 
3. Gulen TA, Guner R, Celikbilek N, Keske S and Tasyaran M: Clinical importance and cost of bacteremia caused by nosocomial multi drug resistant acinetobacter baumannii. Int J Infect Dis 38: 32-35, 2015.

4. Shih MJ, Lee NY, Lee HC, Chang CM, Wu CJ, Chen PL, Ko NY and Ko WC: Risk factors of multidrug resistance in nosocomial bacteremia due to Acinetobacter baumannii: A case control study. J Microbiol Immunol Infect 41: 118-123, 2008.

5. Tas T, Kocoglu E, Mengeloglu Z, Bucak O and Karabörk S: Investigation of in-vitro susceptibility of multidrug-resistant Acinetobacter baumannii strains isolated from clinical specimens to tigecycline. Bosn J Basic Med Sci 13: 266-270, 2013.

6. Minandri F, D'Arezzo S, Antunes LC, Pourcel C, Principe L, Petrosillo $\mathrm{N}$ and Visca P: Evidence of diversity among epidemiologically related carbapenemase-producing Acinetobacter baumannii strains belonging to international clonal lineage II J Clin Microbiol 50: 590-597, 2012.

7. Castanheira M, Wanger A, Kruzel M, Deshpande LM and Jones RN: Emergence and clonal dissemination of OXA-24and OXA-58-Producing Acinetobacter baumannii Strains in Houston, Texas: Report from the SENTRY Antimicrobial Surveillance Program. J Clin Microbiol 46: 3179-3180, 2008.

8. Lu PL, Siu LK, Chen TC, Ma L, Chiang WG, Chen YH, Lin SF and Chen TP: Methicillin-resistant Staphylococcus aureus and Acinetobacter baumannii on computer interface surfaces of hospital wards and association with clinical isolates. BMC Infect Dis 9: $164,2009$.

9. Clinical and Laboratory Standards Institute: Performance Standards for Antimicrobial Susceptibility Testing: Twenty-Second Informational Supplement M100-S22. CLSI 32: $64-65,2012$

10. Koeleman JG, Stoof J, Biesmans DJ, Savelkoul PH and Vandenbroucke-Grauls CM: Comparison of amplified ribosomal DNA restriction analysis, random amplified polymorphic DNA analysis and amplified fragment length polymorphism fingerprinting for identification of Acinetobacter genomic species and typing of Acinetobacter baumannii. J Clin Microbiol 36 2522-2529, 1998

11. Hoban DJ, Bouchillon SK and Dowzicky MJ: Antimicrobial susceptibility of extended-spectrum beta-lactamase producers and multidrug-resistant Acinetobacter baumannii throughout the United States and comparative in vitro activity of tigecycline, a new glycylcycline antimicrobial. Diagn Microbiol Infect Dis 57: 423-428, 2007.

12. López-Alvarez B, Martín-Laez R, Fariñas MC, Paternina-Vidal B García-Palomo JD and Vázquez-Barquero A: Multidrug-resistant Acinetobacter baumannii ventriculitis: Successful treatment with intraventricular colistin. Acta Neurochir (Wien) 151 $1465-1472,2009$

13. Kwa AL, Loh C, Low JG, Kurup A and Tam VH: Nebulized colistin in the treatment of pneumonia due to multidrug-resistant Acinetobacter baumannii and Pseudomonas aeruginosa. Clin Infect Dis 41: 754-757, 2005

14. Ho CM, Ho MW, Chi CY, Lin CD, Lin CW, Tseng SP, Teng LJ, Chang HY, Chang HL, Chang YF, et al: Repeated colonization by multi-drug-resistant Acinetobacter calcoaceticus- $A$. Baumannii complex and changes in antimicrobial susceptibilities in surgical intensive care units. Surg Infect (Larchmt) 14: $43-48,2013$

15. Celik IH, Oguz SS, Demirel G, Erdeve O and Dilmen U: Outcome of ventilator-associated pneumonia due to multidrug-resistant Acinetobacter baumannii and Pseudomonas aeruginosa treated with aerosolized colistin in neonates: A retrospective chart review. Eur J Pediatr 171: 311-316, 2012.

16. Moland ES, Craft DW, Hong SG, Kim SY, Hachmeister L, Sayed SD and Thomson KS: In vitro activity of tigecycline against multidrug-resistant Acinetobacter baumannii and selection of tigecycline-amikacin synergy. Antimicrob Agents Chemother 52: 2940-2942, 2008

17. D'Arezzo S, Capone A, Petrosillo N, Visca P; GRAB Ballardini M, Bartolini S, Bordi E, Di Stefano A, Galiè M, et al: Epidemic multidrug-resistant Acinetobacter baumannii related to European clonal types I and II in Rome (Italy). Clin Microbiol Infect 15: 347-357, 2009.

18. Garnacho-Montero J and Amaya-Villar R: Multiresistant Acinetobacter baumannii infections: Epidemiology and management. Curr Opin Infect Dis 23: 332-339, 2010.
19. Hou $C$ and Yang F: Drug-resistant gene of blaOXA-23, blaOXA-24, blaOXA-51 and blaOXA-58 in Acinetobacter baumannii. Int J Clin Exp Med 8: 13859-13863, 2015.

20. Poirel L,Pitout JD and Nordmann P: Carbapene-mases: Molecular diversity and clinical consequences. Future Microbio 2: 501-512, 2007.

21. Sinha M and Srinivasa H: Mechanisms of resistance to carbapenems in meropenem- resistant Acinetobacter isolates from clinical samples. Ind J Med Microbiol 25: 121-125, 2008.

22. Chretien FC and Dubois R: Effect of nomegestrol acetate on spinability, ferning and mesh dimension of midcycle cervical mucus. Contraception 43: 55-65, 1991.

23. Radberg G, Nilsson LE and Svensson S: Development of quinolone-imipenem cross resistance in Pseudomonas aeruginosa during exposure to ciprofloxacin. Antimicrob Agents Chemother 34: 2142-2147, 1990.

24. Barclay ML, Begg EJ, Chambers ST and Peddie BA: The effect of aminoglycoside-induced adaptive resistance on the antibacterial activity of other antibiotics against Pseudomonas aeruginosa in vitro. J Antimicrob Chemother 38: 853-858, 1996.

25. Prasad SV, Ballal M and Shivananda PG: Induction of resistance to fluoroquinolones in clinical and environmental isolates of Pseudomonas aeruginosa. Indian J Pathol Microbiol 50: 94-96, 2007.

26. De Vecchi E, Nicola L, Zucchetti E and Drago L: In vitro induction of resistance by tissue concentrations of azithromycin, clarithromycin, cefixime and amoxicillin/clavulanate in clinical isolates of Streptococcus pyogenes. J Chemother 18: 379-388, 2006.

27. Miller K, O'Neill AJ and Chopra I: Response of Escherichia coli hypermutators to selection pressure with antimicrobial agents from different classes. J Antimicrob Chemother 49: 925-934, 2002.

28. Tripodi MF, Durante-Mangoni E, Fortunato R, Utili R and Zarrilli R: Comparative activities of colistin, rifampicin, imipenem and sulbactam/ampicillin alone or in combination against epidemic multidrug-resistant Acinetobacter baumannii isolates producing OXA-58 carbapenemases. Int J Antimicrob Agents 30: 537-540, 2007

29. Jeon BC, Jeong SH, Bae IK, Kwon SB, Lee K, Young D, Lee JH, Song JS and Lee SH: Investigation of a nosocomial outbreak of imipenem-resistant Acinetobacter baumannii producing the OXA-23 beta-lactamase in Korea. J Clin Microbiol 43: 2241-2245, 2005

30. Chiu CH, Lee HY, Tseng LY, Chen CL, Chia JH, Su LH and Liu SY: Mechanisms of resistance to ciprofloxacin, ampicillin/sulbactam and imipenem in Acinetobacter baumannii clinical isolates in Taiwan. Int J Antimicrob Agents 35: 382-386, 2010.

31. Liu YH, Kuo SC, Lee YT, Chang IC, Yang SP, Chen TL and Fung CP: Amino acid substitutions of quinolone resistance determining regions in GyrA and ParC associated with quinolone resistance in Acinetobacter baumannii and Acinetobacter genomic species 13TU. J Microbiol Immunol Infect 45: 108-112, 2012.

32. Wieczorek P, Sacha P, Hauschild T, Zorawski M, Krawczyk M and Tryniszewska E: Multidrug resistant Acinetobacter baumannii-the role of AdeABC (RND family) efflux pump in resistance to antibiotics. Folia Histochem Cytobiol 46: 257-267, 2008.

33. Lin L, Ling BD and Li XZ: Distribution of the multidrug efflux pump genes, adeABC, adeDE and adeIJK, and class 1 integron genes in multiple-antimicrobial-resistant clinical isolates of Acinetobacter baumannii-Acinetobacter calcoaceticus complex. Int J Antimicrob Agents 33: 27-32, 2009.

34. Hou PF, Chen XY, Yan GF, Wang YP and Ying CM: Study of the correlation of imipenem resistance with efflux pumps AdeABC, AdeIJK, AdeDE and AbeM in clinical isolates of Acinetobacter baumannii. Chemotherapy 58: 152-158, 2012.

35. Magnet S, Courvalin P and Lambert T: Resistance-nodulation-cell division-type efflux pump involved in aminoglycoside resistance in Acinetobacter baumannii strain BM4454. Antimicrob Agents Chemother 45: 3375-3380, 2001.

36. Zhou Y, Wu X, Zhang X, Hu Y, Yang X, Yang Z and Wang M: Genetic Characterization of ST195 and ST365 Carbapenem-Resistant Acinetobacter baumannii Harboring blaOXA-23 in Guangzhou, China. Microb Drug Resist 21: 386-390, 2015. 